\title{
Avaliação da degradação de fachadas: Estudo de caso em duas edificações no Bairro do DORON - Salvador/BA
}

\author{
P.C. NUNES, ${ }^{1}$; P.V.G. FREITAS ${ }^{2 *}$; A. R. A. OMORE ${ }^{3}$, M. A. MACHADO ${ }^{3}$; V. A. COELHO ${ }^{4}$; \\ F. G.S. SILVA ${ }^{5}$ \\ *Autor de Contato: priscilav@,fieb.org.br \\ ${ }^{1}$ Pós-Graduanda em Engenharia de Avaliações e Perícias, UNIJORGE, Salvador, Brasil \\ ${ }^{2}$ Área de construção civil, SENAI CIMATEC, Salvador, Brasil \\ ${ }^{3}$ Graduado(a) em Engenharia Civil, Escola Politécnica, Universidade Federal da Bahia, Salvador, Brasil \\ ${ }^{4}$ PPEC, Escola Politécnica, Universidade Federal da Bahia, Salvador, Brasil \\ ${ }^{5}$ Departamento de Construção e Estruturas, Universidade Federal da Bahia, Salvador, Brasil
}

\section{RESUMO}

O trabalho pretendeu avaliar a degradação das fachadas do bairro popular Doron Salvador/BA. Dentre os edifícios multifamiliares que compõe o território estudado, foram selecionados dois, nos quais recaiu um estudo mais detalhado, onde, para além de identificar as anomalias existentes, procurou-se definir as possíveis causas, a fim de determinar as melhores manutenções, preservando a funcionalidade e a estética das fachadas. As principais anomalias encontradas foram descoloração, manchas, fissurações, fungos, destacamento da pintura e eflorescência, originadas pela falta de qualidade no projeto e dos materiais, aliados a uma inexistente manutenção preventiva e reparativa, o que contribui para a sua degradação.

Palavras-chave: Fachadas; Degradação; Recuperação 


\title{
Evaluation of façade degradation: Case study in two buildings in the neighborhood of DORON - Salvador/BA
}

\begin{abstract}
The work aimed to evaluate the facade degradation of the popular neighborhood Doron at Salvador / BA. Among the multifamily buildings that make up the studied territory, two were selected, which included a more detailed study, where, in addition to identifying the existing anomalies, possible causes were defined, in order to determine the best maintenance, preserving the functionality and aesthetics of the facades. The main anomalies found were discoloration, stains, cracking, fungus, painting detachment and efflorescence, caused by the lack of quality in the design and materials, coupled with a absence of preventive and reparative maintenance, which contributes to its degradation.
\end{abstract}

Keywords: Facades; Degradation; Restoration.

\section{Evaluación de la degradación de fachadas: estudio de caso en dos edificios en Bairro do DORON - Salvador / BA}

\begin{abstract}
RESUMEN
Este trabajo tuvo como objetivo evaluar la degradación de las fachadas del popular barrio Doron Salvador / BA. Entre las edificaciones multifamiliares que componen el territorio estudiado, se seleccionaron dos, en las que se realizó un estudio más detallado, donde, además de identificar las anomalías existentes, se buscó definir las posibles causas con el fin de determinar el mejor mantenimiento, preservando la funcionalidad y estética de las fachadas. Las principales anomalías encontradas fueron decoloración, manchas, grietas, hongos, desprendimiento de pintura $\mathrm{y}$ eflorescencias, provocadas por la falta de calidad en el diseño y materiales, combinado con un inexistente mantenimiento preventivo y reparador, lo que contribuye a su degradación.
\end{abstract}

Palabras clave: Fachadas; Degradación; Recuperación. 


\section{INTRODUÇÃO}

Com o crescimento populacional cada vez maior, o crescimento habitacional também ocorre proporcionalmente e de maneiras desordenadas devido aos diferentes perfis e realidades das famílias. Com isso, se percebe a importância da construção das cidades e em como atender essa demanda. Com o crescimento desordenado, alguns problemas ocorrem, como é o caso da carência da habitação de baixo custo. Para as pessoas, os conjuntos habitacionais têm sido um meio de adquirir moradia própria.

$\mathrm{Na}$ grande maioria, os conjuntos, por possuírem objetivos econômicos de baixos custos - para construção e totalização de seus imóveis, são planejados com composições bastante simplificadas, tanto de sua arquitetura, contempladas por suas formas com altura baixa, como pela composição de materiais utilizados. Essa redução, é uma das causas, aliado à falta de manutenção da construção, para o surgimento de patologias de construção nos conjuntos habitacionais. Essas patologias são facilmente vistas e detectadas nas fachadas desses edifícios.

No entanto, esse cenário tem mudado bastante, devido à exigibilidade da NBR 15575 (ABNT, 2013), conhecida como norma de desempenho, e hoje visa, principalmente, as exigências dos usuários, com base nas condições de habitabilidade das edificações e na sua vida útil, que está relacionada com a manutenção.

A NBR 13755 (ABNT, 2017), define revestimento das fachadas como elemento funcional com papel de proteger a edificação da ação da chuva, umidade, agentes atmosféricos, desgaste mecânico oriundo da ação conjunta do vento e partículas sólidas (exigências associadas a durabilidade do elemento), bem como de acabamento final, complemento das vedações e dar acabamento estético. Sabe-se que o revestimento externo da edificação é um dos sistemas mais exigidos, justamente por estar ligado diretamente a agressividade do meio ambiente e por propriedades físico-químicas dos seus diferentes materiais constituintes. Para manter a capacidade funcional durante a vida útil prevista em projeto, sem os sinais de desgaste do edifício, devem se realizar as intervenções periódicas de manutenção e conservação (BAUER et al, 2011).

ANTUNES (2010) indica como principais causas a omissão de elementos construtivos importantes, várias etapas executadas inadequadamente, não seguimento das especificações de projetos, uso inadequado dos materiais e a ausência de manutenção. E com a incidência de problemas patológicos sobre as fachadas, o desempenho das mesmas vem sendo alterado, e suas funções básicas como valorização estética e econômica do edifício, melhoria de estanqueidade da vedação, regularização e acabamento final da fachada são comprometidas.

Portanto, é essencial o levantamento dos danos, detecção das causas prováveis, e realização de diagnósticos mais rigorosos para sistema de revestimento de fachadas danificados. Os diagnósticos, muitas vezes, são realizados e não compreendidos, seja pela subjetividade ou por falta de capacidade técnica do solicitante, consequentemente são indicadas soluções de reparo inadequado ao tipo de dano identificado. E com isso, a patologia não é resolvida e só gera mais gastos.

\section{OBJETIVOS}

O conhecimento e a identificação das patologias em fachadas é necessária, pois, permite promover meios de prevenção e verificar o risco desta para os seus usuários, subsidiando intervenções de forma mais assertiva, pois, segundo Guimarães (2009) os edifícios antigos que chegaram aos dias de hoje preservando a sua autenticidade são aqueles que tiveram uma manutenção periódica limitada ao que era necessário ser executado, com materiais e técnicas tradicionais originais ou compatíveis da referida época. Logo, o estudo das manifestações patológicas, assim como suas 
causas, efeitos e consequências em qualquer que seja a edificação, é essencial, pois estas edificações podem causar algum dano maior para os seus usuários.

Neste sentido, este trabalho tem por objetivo fazer uma avaliação das manifestações patológicas das fachadas de duas edificações em um conjunto habitacional na cidade de Salvador, capital baiana.

\section{METODOLOGIA}

Este trabalho apresenta dados referentes às manifestações patológicas detectadas em dois edifícios, localizados no bairro Doron na cidade de Salvador/BA. Os edifícios apresentam revestimento em argamassa com acabamentos em pintura. A inspeção dos edifícios (A e B) foi de caráter estritamente visual.

A análise das inconformidades presentes nas fachadas se deu através de visitas ao local, mapeamento fotográfico, análise in loco, identificação e classificação das manifestações patológicas e busca por informações que auxiliasse no diagnóstico dos danos.

\subsection{Caracterização tipológica das edificações}

O bairro Doron foi construído nos anos 80 e é composto por 160 edifícios de 4 pavimentos e 8 apartamentos. Antigamente era considerado um conjunto habitacional, mas com o desenvolvimento econômico do comércio, se tornou um dos bairros da cidade Salvador. A Figura 1 apresenta uma vista geral do bairro.

$\mathrm{O}$ objeto de estudo são as edificações identificadas como A e B, como mostra a Figura 1. Elas foram construídas na mesma época, mas a edificação B já passou por algumas manutenções na fachada, diferente do prédio A.

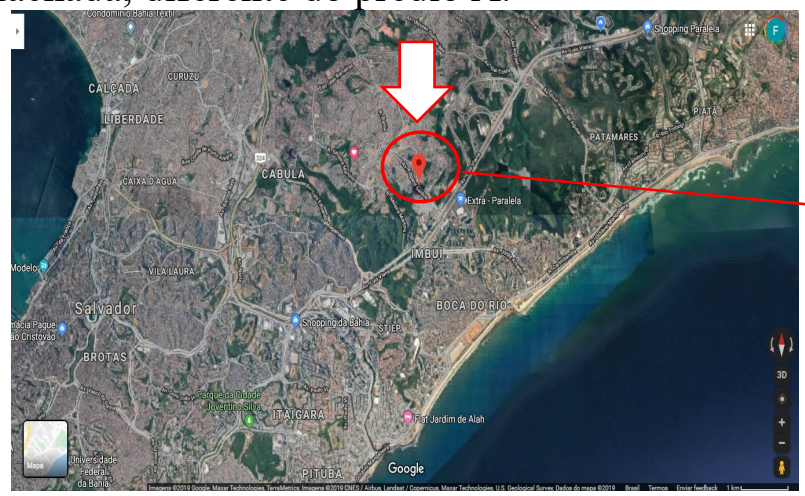

Fonte: GoogleMaps (2019)

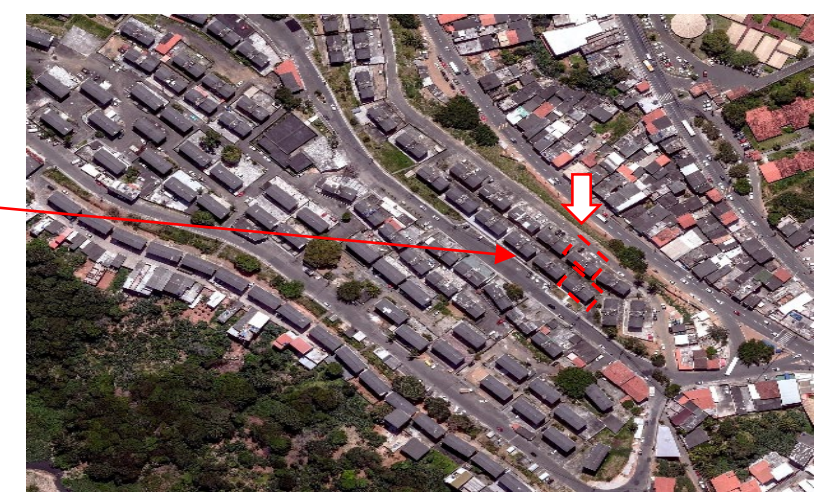

Fonte: Geopolis - CONDER (2019)

Figura 1 - Vista Geral do bairro Doron

\subsection{Orientação das fachadas}

Os edifícios A e B apresentam as fachadas orientadas no mesmo sentido, sendo a frontal sudoeste e a posterior nordeste, sendo apresentadas nas Figuras 2 a 5. 


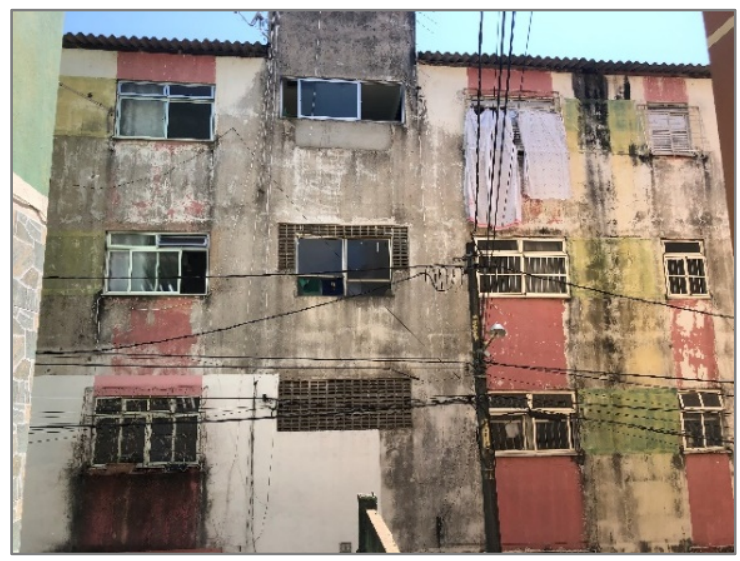

Figura 2 - Edifício A, fachada frontal

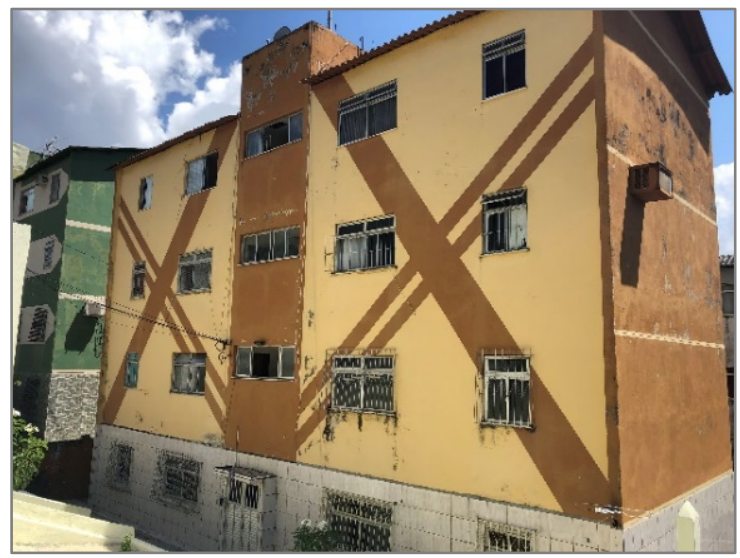

Figura 4 - Edifício B, fachada frontal

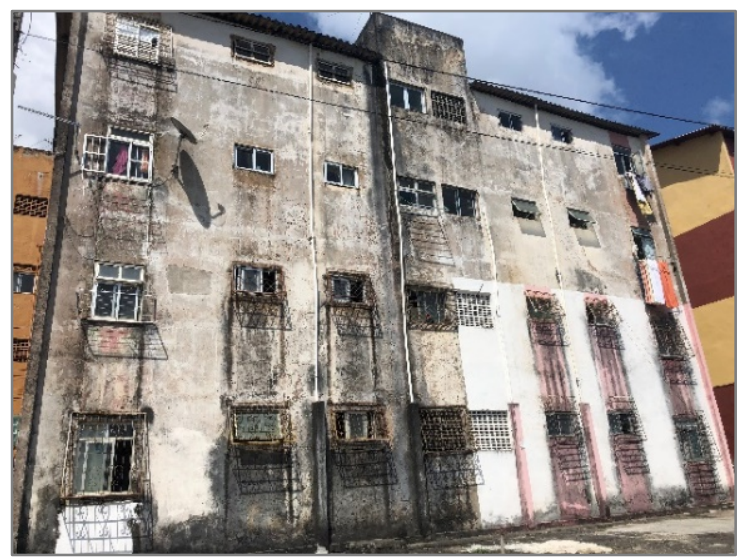

Figura 3 - Edifício A, fachada posterior

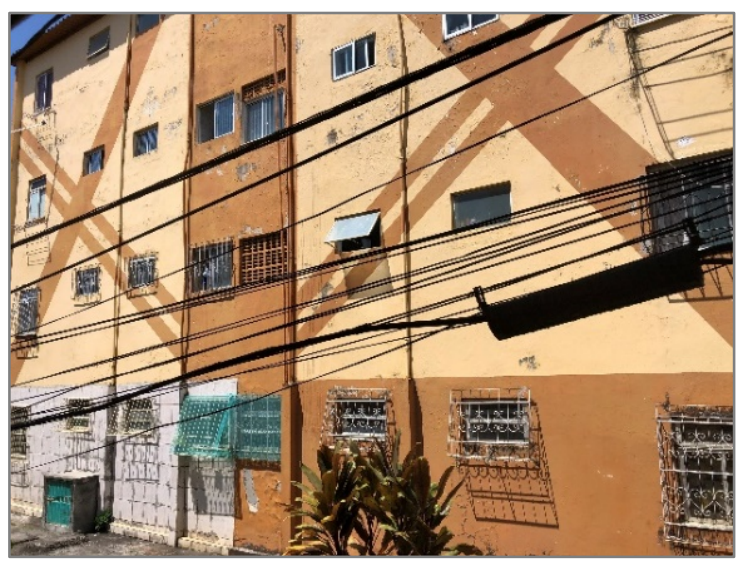

Figura 5 - Edifício B, fachada posterior

\section{RESULTADOS E DISCUSSÃO}

As ações externas as quais as edificações estão submetidas como a temperatura, radiação solar, vento, umidade modificam as propriedades dos materiais constituintes das fachadas. Afetando diretamente a maneira como se dá a absorção de água e capilaridade pelas vedações e como esses componentes reagem à variação de temperatura (LIMA et al., 2014).

\subsection{Descoloração}

Como pode-se observar nas Figuras 6 a 9, as fachadas apresentam descoloração do revestimento, caracterizada pela perda parcial de cor de uma película da pintura. Essa patologia tem algumas causas como o processo natural de envelhecimento, ação contínua de agentes climáticos e o contato com agentes químicos.

Na Figura 6 pode-se observar ainda a presença de umidade na proximidade da cobertura, o que pode ser originado de uma falta de impermeabilização da laje, ou deslocamento de telhas. 


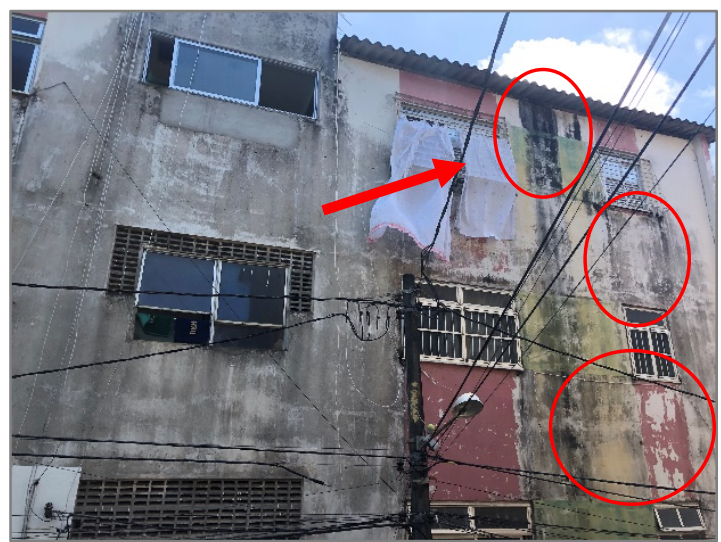

Figura 6 - Descoloração na fachada frontal, Edifício A

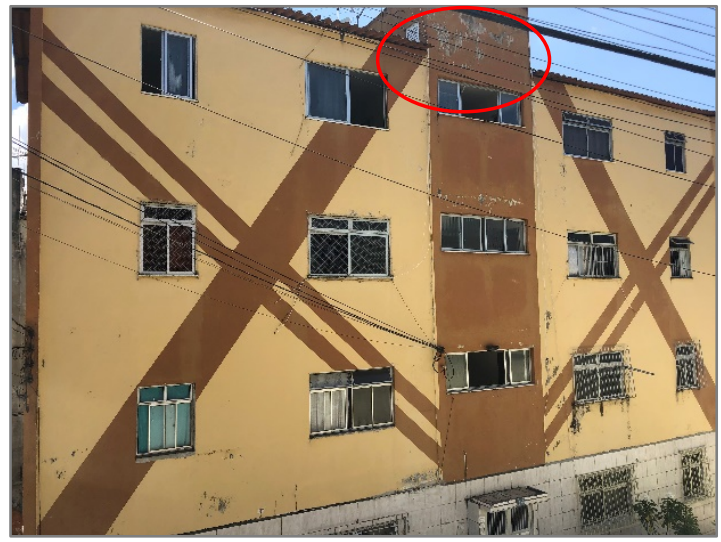

Figura 8 - Descoloração na fachada frontal, Edifício B

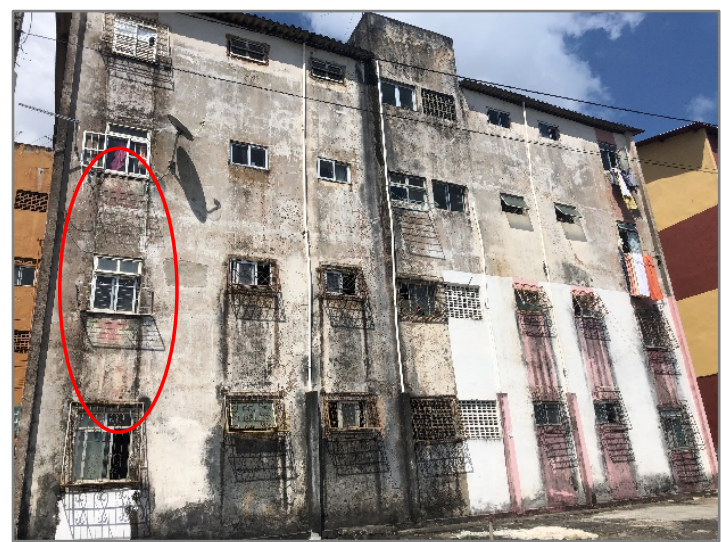

Figura 7 - Descoloração na fachada posterior, Edifício A

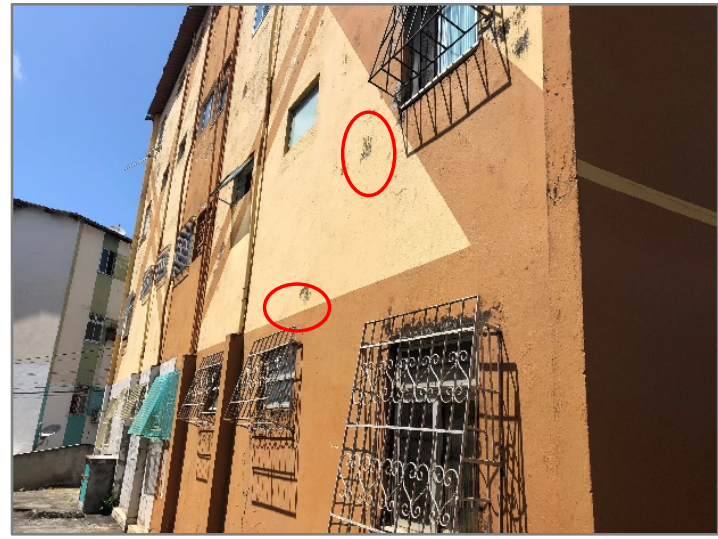

Figura 9 - Descoloração na fachada posterior, Edifício B

\subsection{Manchas}

Em todas as fachadas analisadas, como apresentado nas Figuras 10 a 12, foram encontradas manchas escuras, o qual o principal responsável é a poluição atmosférica, através do recobrimento dos revestimentos por pó, fuligem e partículas contaminantes. Alguns fatores também contribuem para essa patologia que são o vento (dispersa as partículas podendo ocorrer acumular na fachada), a chuva (ao escorrer sobre a fachada pode acumular nos depósitos), a porosidade do material de revestimento (a água pode penetrar nos poros) e a forma das fachadas (nas superfícies horizontais a deposição de partículas é maior) (CHAVES, 2009). 


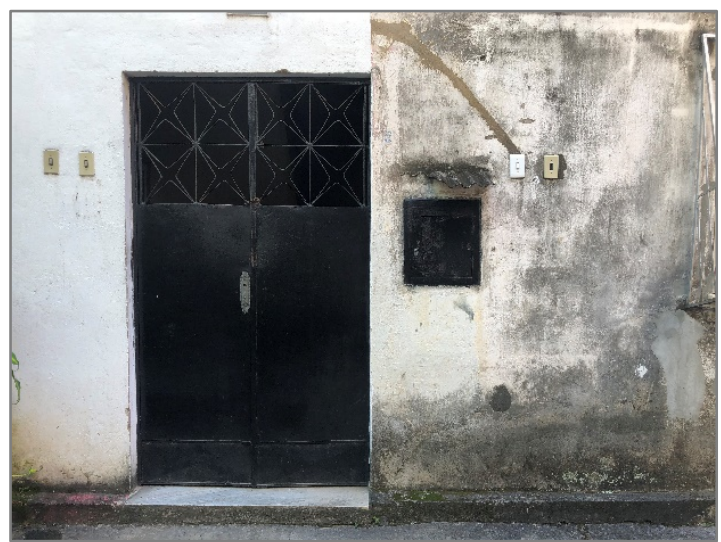

Figura 10 - Manchas na fachada frontal, Edifício A

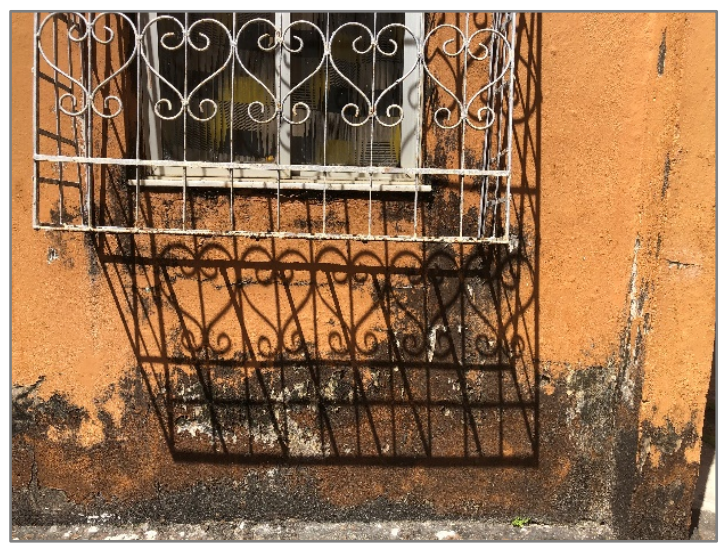

Figura 12 - Manchas na fachada posterior, Edifício B

\subsection{Fissuração}

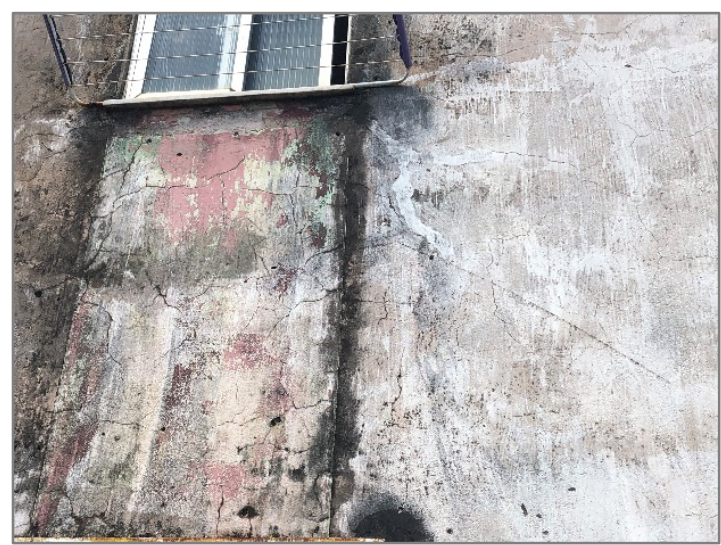

Figura 11 - Manchas na fachada posterior, Edifício A

Durante a inspeção as edificações, constatou-se ainda a existência de fissuras generalizadas no revestimento da fachada posterior do Edifício A, como mostram as Figuras 13 e 14. No Edifício B não foram encontradas fissuras. $\mathrm{O}$ aparecimento de fissuras afeta a impermeabilização, que, ao permitir o acesso da água e de outros agentes agressivos, reduz a durabilidade do revestimento. Elas podem ser originadas devido à perda de água da argamassa após a aplicação, hidratação tardia de cal magnesiana e expansões de material graúdo, como torrões de argila na variação de umidade ou materiais com dilatação muito diferente, frente às mudanças de temperatura (TELES, 2010). O que também podemos observar nas edificações é a utilização de arenoso no revestimento e, segundo Chaves (2009), a fissuração está intimamente relacionada com excesso do teor de finos e com a espessura da camada argamassada. 


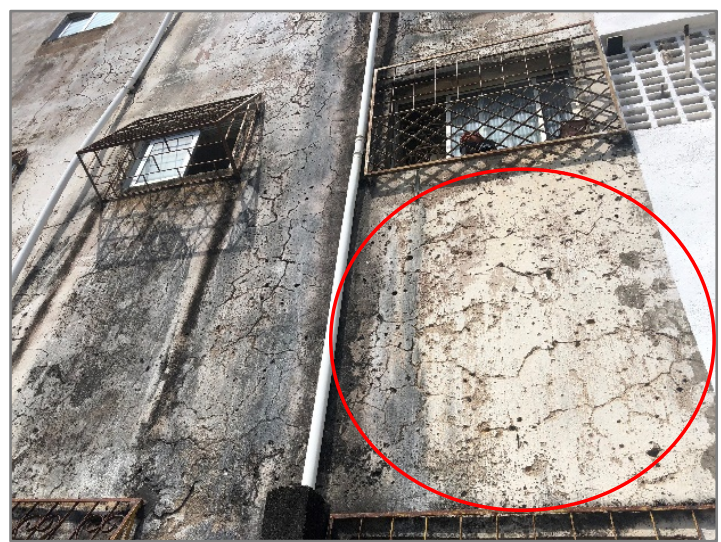

Figura 13 - Fissuras na fachada frontal, Edifício A

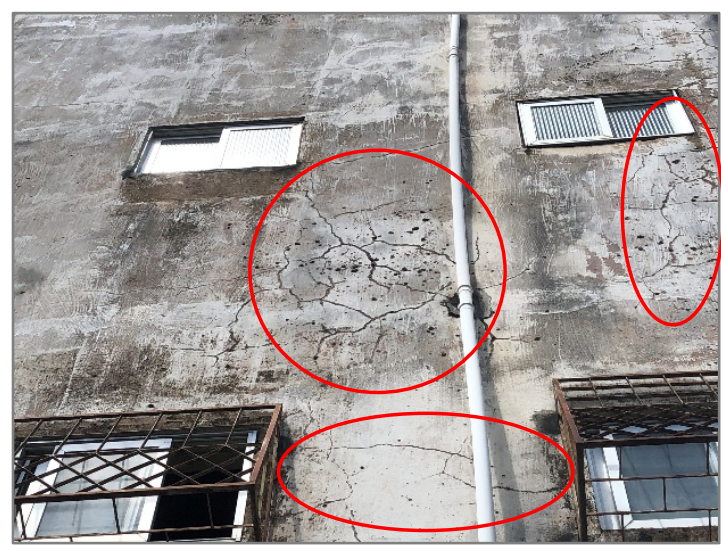

Figura 14 - Fissuras na fachada posterior, Edifício A

\subsection{Desenvolvimento de fungos}

De modo geral, constatou-se desenvolvimento de fungos em ambas as edificações (Figuras 15 a 18). Para o aparecimento de fungos é necessário a exposição de condições favoráveis, como umidade e temperatura elevada, ausência de radiação solar e ventilação e o revestimento ser de cor clara, com baixo teor de fungicidas.

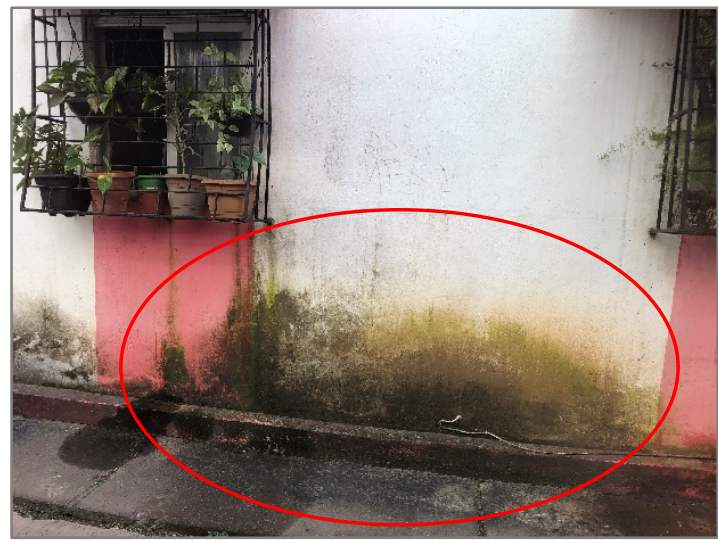

Figura 15 - Agentes biológicos, fachada frontal Edifício A

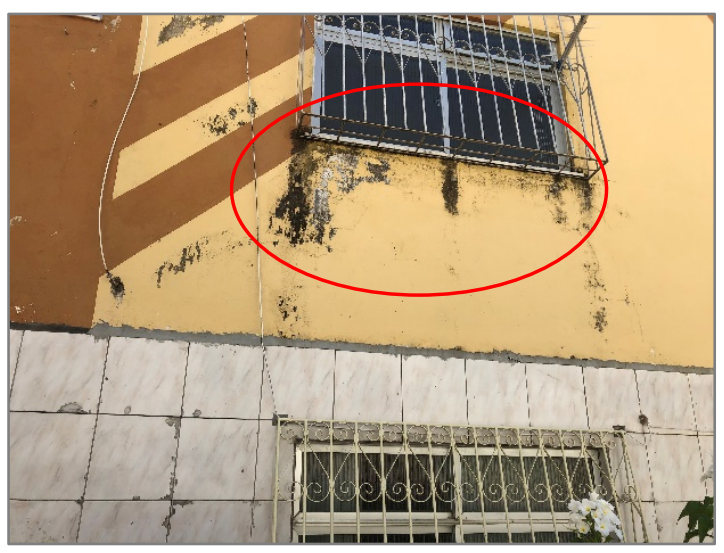

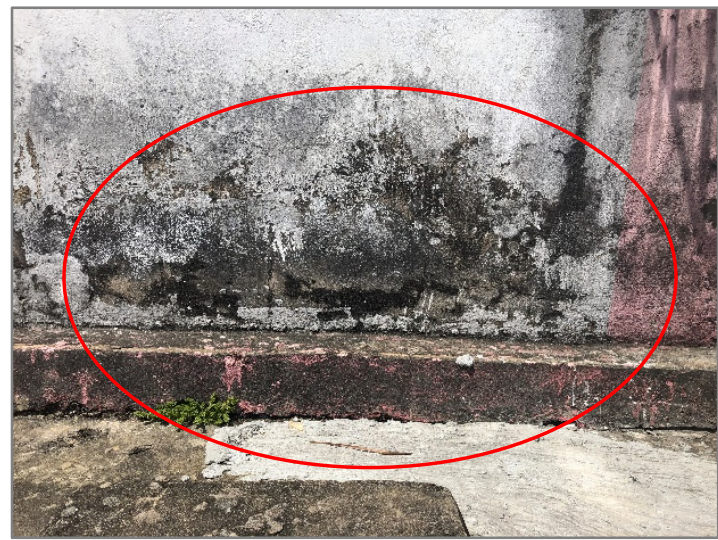

Figura 16 - Agentes biológicos, fachada posterior, Edifício A

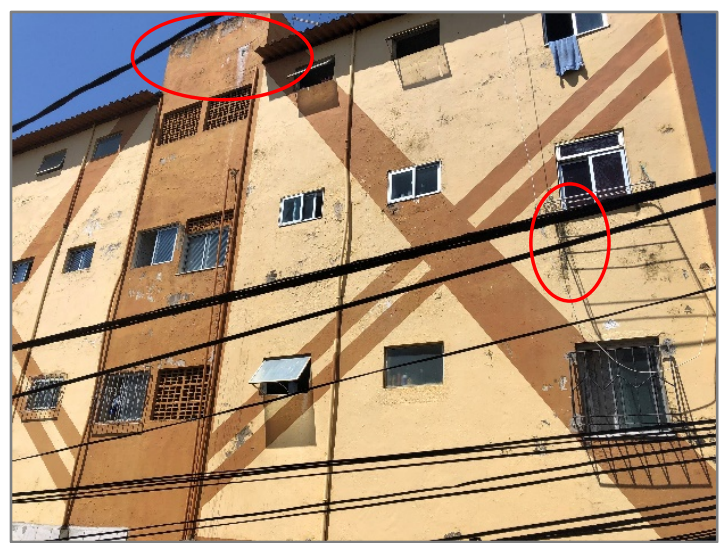


Figura 17 - Agentes biológicos, fachada frontal Edifício B
Figura 18 - Agentes biológicos, fachada posterior, Edifício B

\subsection{Destacamento da pintura}

As Figuras 19 e 20 mostram o destacamento da pintura nas fachadas posterior das edificações, ou seja, as fachadas nascentes que estão expostas constantemente as intempéries. Os raios ultravioletas são prejudiciais aos pigmentos das tintas e, quando combinados com altas temperaturas causam a rápida degradação da película sintética pela perda de elasticidade e enfraquecimento do filme. Consequentemente acontece, também, dilatação diferencial entre as camadas sobrepostas, expostas ao calor. Com o passar do tempo formam-se fissuras capilares com a migração de agentes degradantes do meio para o interior do suporte (BEZERRA, 2010).

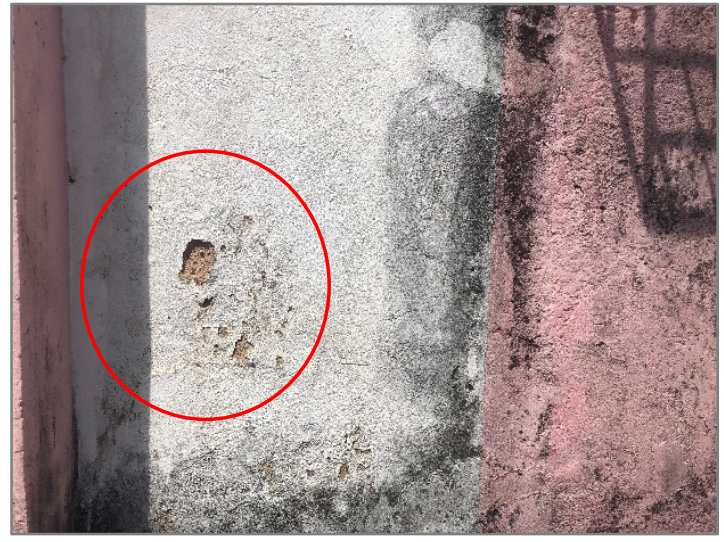

Figura 19 - Destacamento da pintura, Edifício A

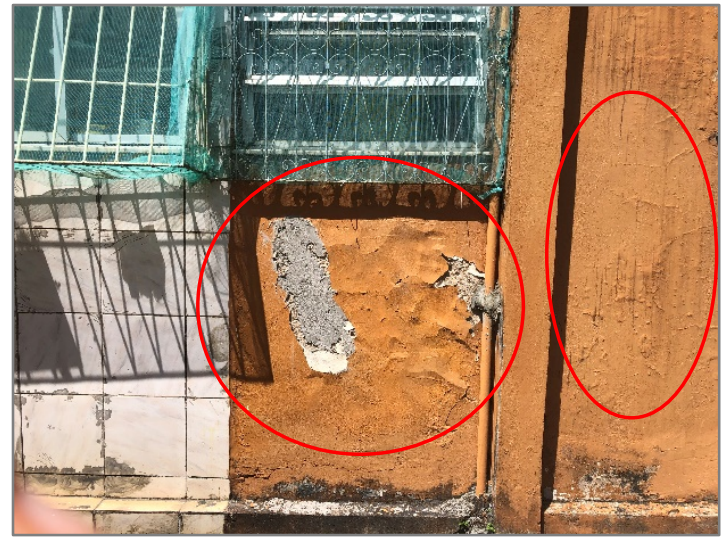

Figura 20 - Destacamento da pintura, Edifício B

\subsection{Eflorescências}

A eflorescência é caracterizada pelo aparecimento de depósitos cristalinos/salinos no revestimento. Para que ocorra a formação, Bauer (1997) e Uemoto (1988) afirmam ser necessária a existência simultânea de sais solúveis, água e pressão hidrostática. Nos revestimentos de fachadas, das diversas origens, os sais solúveis podem ser provenientes do rejuntamento da cerâmica. Já a água pode ser originária da fase de execução das diversas camadas do revestimento, da infiltração da água de chuva pelas fissuras, pela condensação de vapor da atmosfera dentro das paredes (SABBATINI; BARROS, 1990).

As eflorescências são, portanto, cristalizações de sais solúveis que se dão à superfície de meios porosos e podemos observá-la na Figura 21 do estudo. Na mesma figura, percebe-se a presença de vegetação o que indica a presença de umidade, que é um dos principais fatores de degradação dos elementos construtivos. 


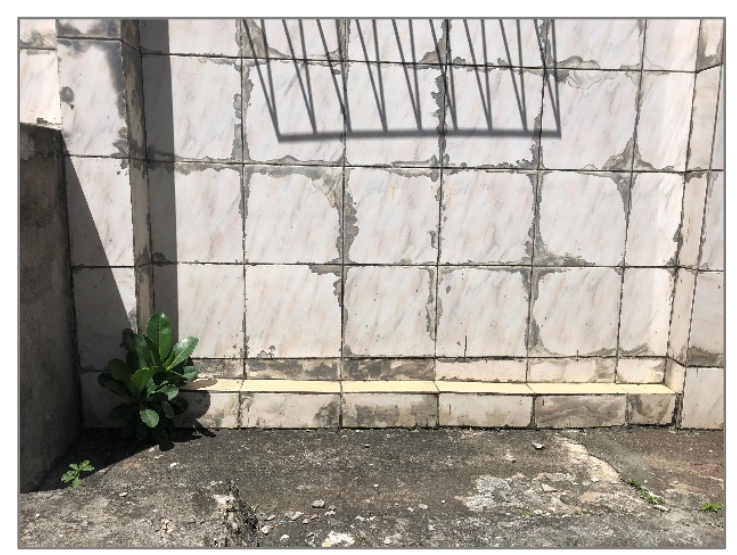

Figura 21 - Manchas na fachada posterior, Edifício B

\section{CONCLUSÕES}

A longo da sua vida útil, todos os edifícios sofrem alterações dimensionais, deslocações e variações de volume, que consequentemente dão origem a tensões, que provêm sobretudo de fenômenos de variação de temperatura e umidade e que refletem no desempenho dos revestimentos exteriores. Neste trabalho, foram descritas as condições atuais de duas edificações no bairro Doron, SalvadorBA. Com a metodologia utilizada foi possível realizar a identificação dos danos e prováveis causas, com o objetivo de ter um diagnóstico que possibilite a determinação das medidas de manutenção corretiva e preventiva, e desta forma, impedir que as patologias se agravem ou até mesmo provoquem outras.

Tais medidas são necessárias, principalmente à edificação A, frente ao estado avançado de degradação das fachadas, ela ainda apresenta suas características originais, necessitando de manutenção e correção das patologias o mais breve possível.

Já o edifício B apresenta melhor estado de conservação, pois passou por algumas manutenções corretivas durante o tempo. Entretanto, ainda necessita de manutenção corretiva com soluções adequadas das patologias encontradas, feito por um profissional capacitado.

De acordo com o estudo realizado foi possível verificar que devido ao uso inadequado de materiais na fachada, aliado a falta de manutenção preventiva e corretiva proporcionaram o alto índice de danos nas fachadas sudoeste e nordeste. Cabe ainda destacar que os detalhes construtivos quando não considerados podem comprometer a edificação com manifestações de danos, como foi constatado a deficiência no sistema de impermeabilização das lajes e do reservatório superior.

É importante ressaltar que, tendo em consideração a idade da edificação, seria de se esperar o aparecimento de diversas patologias, principalmente ocasionadas pelos agentes externos como a umidade, o aparecimento de fissuras e o destacamento da argamassa. Desta forma, é importante estudos com o intuito de utilizar técnicas e materiais que permitam manter o desempenho esperado ao longo de toda a sua vida útil das edificações.

\section{REFERÊNCIAS}

ABNT - Associação Brasileira de Normas Técnicas. (2013). NBR 15575-4: Edifícios habitacionais - Desempenho Parte 4: Requisitos para os sistemas de vedações verticais internas e externas SVVIE. Rio de Janeiro. 
ABNT - Associação Brasileira de Normas Técnicas. (2017). NBR 13755: Revestimentos de paredes externas e fachadas em com placas cerâmicas e com utilização de argamassa colanteProcedimento. Rio de Janeiro.

ANTUNES, G. R.(2010). Estudo de manifestações patológicas em revestimento de fachada em Brasília-sistematização da incidência de casos. Dissertação. Universidade de Brasília, Brasília: DF (BRASIL), p. 199.

BAUER, E.; CASTRO, E. K. ANTUNES, G. R. (2011), "Processo de identificação das manifestações patológicas em fachadas com revestimento cerâmico" in: IX Simpósio Brasileiro de Tecnologia de Argamassas, Belo Horizonte, Minas Gerais.

BAUER, R.J.F (1997). "Patologia em revestimento de argamassa inorgânica”. In: CONGRESSO IBEROAMERICANO DE PATOLOGIA DAS CONSTRUÇÕES, UFRGS, Anais., Porto Alegre (BRASIL), pp. 389-96.

BEZERRA,F.A (2010). "As cores das Fachadas de Edificações Históricas Pintadas a Cal". Dissertação. Universidade Federal de Santa Catarina, Florianópolis: SC (BRASIL), p. 139.

CHAVES, A. M. V. A. (2009). "Patologia e reabilitação de revestimentos de fachadas". Dissertação. Universidade do Minho: Escola de Engenharia, Braga (PORTUGAL), pp.176.

GUIMARÃES, J.P (2009). "Técnicas Tradicionais de Construção, Anomalias e Técnicas de Intervenção em Fachadas e Coberturas de Edifícios Antigos". Dissertação. Universidade de Trásos-Montes e Alto Douro, Portugal.

LIMA, G. E. S. L; SOUZA, K.D; T, A. C. G. (2014). "Investigação e Diagnóstico de Patologias Relacionadas às Fachadas de uma Edificação" In: XV Encontro Nacional de Tecnologia do Ambiente Construído. Alagoas, Maceió, BRASIL.

SABBATINI, F.H.; BARROS, M.M.S.B. (1990). "Recomendações para a produção de revestimentos cerâmicos para paredes de vedação em alvenaria". Relatório Técnico R6-06/90, Escola Politécnica - Universidade de São Paulo, São Paulo, Brasil.

Teles, C. D. M (2010). "Inspeção de fachadas históricas. levantamento de materiais e danos de argamassas". Tese de Doutorado. Programa de Pós-Graduação em Arquitetura e Urbanismo e Área de Concentração em Arquitetura, Urbanismo e Tecnologia - Escola de Engenharia de São Carlos da Universidade de São Paulo, São Paulo, Brasil.

UEMOTO, K. L. (1988). "Patologia: Danos causados por eflorescência" In: Tecnologia de Edificações. São Paulo: SP (BRASIL), pp.561-64. 